\title{
Affecting Factors of Soil Microorganisms and Their Research Prospects
}

\author{
Wang Lide ${ }^{1,2,3}$, Wu Chunrong ${ }^{1,2, ~ *, ~ S o n g ~ D a c h e n g ~}{ }^{1,2}$, Wang Jia ${ }^{3}$, He Hongsheng ${ }^{3}$, Guo Chunxiu ${ }^{1,2}$, \\ Wang Fangling ${ }^{1,2}$ \\ ${ }^{1}$ Gansu Desert Control Research Institute, Lanzhou, People's Republic of China \\ ${ }^{2}$ Gansu Hexi Corridor Forest Ecosystem National Research Station, Wuwei, People's Republic of China \\ ${ }^{3}$ College of Forestry, Gansu Agricultural University, Lanzhou, People's Republic of China
}

Email address:

wldzy69@163.net (Wang Lide),wucr_1984@163.com (Wu Chunrong)

${ }^{*}$ Corresponding author

\section{To cite this article:}

Wang Lide, Wu Chunrong, Song Dacheng, Wang Jia, He Hongsheng, Guo Chunxiu, Wang Fangling. Affecting Factors of Soil Microorganisms and Their Research Prospects. Frontiers in Environmental Microbiology. Vol. 7, No. 3, 2021, pp. 74-79. doi: $10.11648 /$ j.fem.20210703.11

Received: July 4, 2021; Accepted: July 19, 2021; Published: July 24, 2021

\begin{abstract}
There are many factors affecting the uncertainty of soil microorganisms. This paper aims at reviewing the influencing factors and research progress of soil microorganisms, such as bacteria, fungi and actinomycetes, soil microbial biomass, such as microbial biomass carbon, microbial biomass nitrogen and microbial biomass $\mathrm{P}$, in the ecological distribution of Soil microbes has been discussed from the aspects of time, space and plant communities etc., focused on effects of natural factors including soil moisture, soil temperature, soil $\mathrm{PH}$, soil nutrients, soil salinity, etc. and artificial measures including fertilization and spraying rare earth elements, grazing, different utilization and tillage practices, crop rotation, burning, fencing, tourism trampling, soil pollution, etc. on soil microbial. Although there are many reports about soil microbiology, overall it is still limited. And look into the distance for future research by combining with our project team for many years of work.
\end{abstract}

Keywords: Soil Microorganism, Soil Microbes, Microbial Biomass, Distribution Characteristics, Influencing Factors, Research Outlook

\section{Introduction}

Soil microorganism is an important part of ecological system, is the core of the soil ecosystem, mainly plays the role of extensive decomposition, is involved in the regulation of soil nutrient cycling directly or indirectly [1], the energy flow [2], organic matter conversion [3], the formation of soil fertility [4], degradation of pollutants and environmental purification etc [5], especially play a leading role in the transformation of material and energy flow in ecosystem process, which has great biological chemical activity [6]. The soil is the stronghold of the microbial life, the components of soil microbial are complex, various and large in quantity. According to Whitman research estimates, there is about 2.6 $\times 1029$ prokaryotic cells the global soil [7]. In addition, the function of soil microbial is complicated and various, it makes up the earth's most abundant biological recourse, it is also the most important gene resource library and metabolite Library [8]. The distribution of soil microbial community diversity, pattern, and important element in circulation, has been paid great attention to by scholars of soil science, the ecology and microbiology and other fields, and become the front and hotspot of current research.

Study on Soil Microbiology generally includes soil microbial classification and soil microbial biomass. The classification of soil microorganism in general refers to soil bacteria, fungi and actinomycetes, includes everything else that is less than $5 \times 103 \mathrm{um} 3$ biology. Soil microbial biomass is the total soil microbial biomass. Main includes the soil microbial biomass carbon, soil microbial biomass nitrogen and soil microbial biomass phosphorus, it's part of living soil organic matter, but the large animal and plant body such as root, not to be covered [9]. Soil microbial biomass is the power of soil organic matter and soil nutrients $(\mathrm{C}, \mathrm{N}, \mathrm{P}, \mathrm{S})$ 
transformation and cycle, it participates in the regulation decomposition of organic matter and the formation of humus, it also regulates and controls the biochemical process of the energy and nutrient cycling in soil, which is an important plant nutrient reserves [10].

The soil microorganism is the regulation of soil nutrient cycle and energy flow in soil ecosystem; it is also a part of organic matter and available nutrients, which is the most active part of the soil, and play important role in the metabolic process of soil. Therefore, it is very necessary to find out the number of microorganisms in soil, to explore the function of soil microbes, to mine and screen the application of beneficial soil microbial resources for understanding soil microorganisms and its relationship with environment.

\section{Affecting Factors of Soil Microbiology}

\subsection{Effect of Physicochemical Factors on Soil Microorganism}

The physical and chemical properties affect greatly of the soil microorganisms [11-15]. In soil ecosystem, soil microbial biomass carbon content has varied greatly. There is $110 \sim 2240 \mathrm{~kg}$ per hectare of topsoil [11], soil microbial biomass carbon increases by soil water content's increase, but soil microbial biomass nitrogen reduces by the volume weight of soil's increase [16]. In the vegetable greenhouse, with the characteristics of high temperature, high humidity also affect significantly on soil microorganisms [17].

The changes of soil quality has great influence on the population of soil bacteria and fungi [13]. Soil bacterial diversity index and soil total organic carbon, total nitrogen, dissolved organic carbon, ammonium nitrogen, available phosphorus, available potassium content and soil $\mathrm{pH}$ value had significant positive correlation. Soil fungal diversity index and soil carbon and nitrogen ratio was significantly positive correlation, and soil $\mathrm{pH}$ value is significant negative correlation. Soil $\mathrm{pH}$ value imbalance is one of the important factors for soil microbial flora imbalance. In vegetable greenhouse cultivation process, high input caused excessive accumulation of soil nutrients, it is directly caused by soil acidification [14]. Different microorganisms have differences adaptability of soil $\mathrm{pH}$ value, such as acidic for fungi, neutrophil for most bacteria [15], therefore, the soil acid-base imbalance will lead to soil microbial flora imbalance.

\subsection{Effects of Fertilization on Soil Microorganism}

The effect of chemical fertilizer, compost, green manure and straw returning on soil microorganism

In soil ecosystem, high and low soil fertility changes the quantity of soil microbial $[18,19]$. Fertilization can increase soil microbial biomass carbon [20], but its effect is connected with number of fertilization, the types of fertilizer and proportion. Fertilization can increase soil microbial biomass carbon, Because after fertilizing, the plants grow quickly, this makes root biomass and root exudates increase, promote soil microbial activity, thus increasing the soil microbial biomass
[21]. Lu Lei studies result show are single fertilizer decreased soil microbial biomass carbon. The results are different from above. Straw application could significantly increase soil microbial biomass carbon, especially under high amount of straw effect more obvious. In the agricultural ecosystem in low fertility fertilizer can promote the growth of plants and other organisms, increase the crop roots and root exudates, thereby promoting the reproduction of the soil microorganism, increase microbial biomass [22].

During the fertilization, soil microbial biomass nitrogen changed significantly, but there are differences in the different processing. In field experiments, Li Zheng studies result show are single green manure or chemical fertilizers decreased soil microbial biomass nitrogen, Especially green manure application combined with chemical fertilizers increased soil microbial biomass nitrogen. In the process of growth and development of tobacco plant, the effects of application ratio of green manure and chemical fertilizer were obvious differences. In comparison with the control at different growth stages, soil microbial biomass nitrogen were increased $3.28 \%-157.69 \%$. Comprehensive effect is better with quantity in $15000 \sim 22500 \mathrm{~kg} / \mathrm{hm}^{2}$ of green manure [23]. But Lu Lei believes that chemical fertilizer decreased soil microbial biomass nitrogen [22], both viewpoints are contradictory each other, it need further study.

In general, fertilization can significantly increase soil microbial biomass phosphorus, but increased the soil microbial biomass phosphorus is also different for different fertilizer. Which may be different with different fertilizer phosphorus content and under the action of microorganism organic fertilizer mineralization and decomposition rate of different relationships, especially organic fertilizer provided nourishment for microbial activity. Microbial blooms will part of organic phosphorus and mineralization of the inorganic phosphorus and assimilated into microbial biomass phosphorus, thus increasing the soil microbial biomass phosphorus. Application of phosphorus fertilizer could promote soil microbial biomass growth, and long-term application of ammonium sulfate and reduced soil microbial biomass [24].

When high quality of compost is put into the soil, it can increase soil microorganism significantly. Because compost is rich in carbon and trace elements, it is necessary for plant growth, it lives in a large number of plants and microorganisms. Which can improve soil physical and chemical properties, such as bulk density, $\mathrm{pH}$, electrical conductivity, porosity, aeration, moisture and granule structure etc, which increase soil organic matter, improve soil microbial diversity, promote nutrient cycling, thus increasing the number of soil microorganisms [4, 19].

A 20-years field experiment on fertilization models, e.g. applications of inorganic fertilizer alone $(\mathrm{CF})$ and inorganic fertilizer combined with wheat straw $(\mathrm{CF} / \mathrm{OM})$ was carried out to study responses of the soil in microbial abundance. Analysis indicates that the abundances of soil ammonia-oxidizing archaea (AOA) and ammonia-oxidizing bacteria (AOB) were significantly higher in treatment $\mathrm{CF}$ and 
treatment $\mathrm{CF} / \mathrm{OM}$ than in the control (no application of fertilizer, $\mathrm{CK}$ ). The population of soil AOB increased at least 16 times while that of soil AOA at best by 3 folds. Fertilizer with straw processing fertilization pattern not only maintain crop yield but also improve the quantity of soil microbial major groups. it shows chemical fertilizers with organic fertilizer is favour for keeping soil microbial diversity, it plays an important role on improving the soil quality [25].

The straw or planting green manure, the two measures often makes the soil microbial biomass increased significantly $[23,26]$, which may stimulate eating bacteria and fungi nematode reproduction. Soil microbial $\mathrm{C} / \mathrm{N}$ ratio is relatively stable, so the $\mathrm{C} / \mathrm{N}$ ratio of plant straw or manure moderate helps make the nutrient cycling and maintained at a relatively stable level [27].

\subsection{Effects of Microbial Fertilizer and Spraying Rare Earth Elements on Soil Microorganisms}

In soil microbial fertilizer and spraying rare earth elements effect on soil microbial activity. In field cultivation conditions, the fermentation liquid and antagonistic bacteria with soil disinfectant application, it can be based on reducing the pathogenic bacteria in soil, and increase the soil antagonistic microorganisms, increase soil microbial diversity of bacteria, improve soil microbial ecological structure [28]. The research result of Zhao Ji shows that, in during the from 6 to 7 month, forage on the spraying quality score of $1000 \times 106$ rare earth, $1 \sim 2$ times, the total number of microorganisms per gram of soil control from $28.3 \times 107$ to $53.4 \times 107$, especially the aerobic bacteria can increase 1 time. The number of actinomycetes and bacillus were increased significantly. When the concentration of spraying rare earth is more than $10000 \times 106$, microbial groups within a certain period of time in the aerobic bacteria, bacillus and actinomycetes quantity will be significantly reduced [29]. So spraying rare earth elements reasonably has a stimulating effect on the number of soil microorganism, but if uses more, will produce negative effects.

\subsection{Effects of Stocking Rate for Soil Microorganisms}

Different grazing intensity not only influences the quantity of microorganisms and soil microorganisms, but also influences various kinds of microorganisms. England mountain grassland, due to because the large number of plants have been trampled into the soil, thereby significantly increased soil microbial biomass [30]. Australia's Northeast Semi-arid Grassland and subtropical grassland grazing, compared with the control and light grazing area, soil microbial biomass carbon decreased by $51 \%$ and $24 \%$ [31].

In Inner Mongolian Region, to investigate the response of meadow steppe ecosystem soil microbes in different grazing intensity. Study of the responses of a grazing intensity of soil microorganisms In Inner Mongolian Region showed that the number of microorganisms in different grazing areas had the same changing trends: bacteria $>$ actinomycetes $>$ fungi. The number of soil microorganisms and soil microbial biomass, such as carbon and nitrogen were higher in grazing areas than that of no-grazing areas. The descending range of the number of bacteria and fungi and the microbial biomasses, such as carbon and nitrogen increased along with the increasing of grazing intensity. Correlation analysis indicated that the number of soil microorganism was significantly correlated with soil microbial biomass. Moderate grazing increases soil microorganisms and soil microbial biomasses [32].

The types of bacillus and filamentous fungi were analyzed under natural grazing gradient in grassland soil by Zhao Ji, it discovered that microbial community diversity index is maximum in the moderate grazing area. In addition, after the 4 years fence, the number of most microorganisms increased and the total number of microorganisms in the grazing intensity was 0,4 and 12 sheep test area increased by $31.1 \%$, $15.6 \%$ and $21.3 \%$ [29].

Therefore, the moderate grazing helps to increase the quantity of soil microbial biomass and soil microorganisms, because moderate grazing increased the exudation of roots, thus increasing the activity of soil microorganisms [33] and over grazing make it decreased [32], the phenomenon consistent with "the intermediate disturbance hypothesis" which is proposed by Connell in 1977. Reasonable grazing contributes to the transformation of soil nutrients; it also has positive meanings in restoration of degraded grassland and promoting the transformation of soil nutrients.

\subsection{Effects of Different Utilization and Tillage Practices on Soil Microorganisms}

Different tillage and usage can change the soil microbial biomass in soil, compared with conventional tillage, no tillage, ditch sowing significantly increased soil microbial biomass carbon, nitrogen, and phosphorus [34]. The good soil structure can significantly increase improve soil microbial activity, in contrast, On the contrary, Tilling the soil not only changes the evolution in soil, but also exposes soil microorganisms into the air, soil microorganism is oxidized by air and shined by sun, so that the soil microflora is changed and the microbial biomass decreased. In the hilly and gully region of the Loess Plateau, no tillage with straw cover than conventional tillage soil microbial biomass nitrogen, phosphorus were increased by $89.6 \%, 29.6 \%$ [35]. But some studies suggest that soil microbial biomass phosphorus in no tillage and conventional tillage had no significant changes [27]. In addition, distantly related crop rotation or catch is conducive to microbial breeding and improve soil microbial function and species diversity, and the influence of soil microbial in rhizosphere associated factor, increase crop production purposes. In general, the long-term effect of these measures is short-term effect. Otherwise, the longer they crop, the more years that they need to repair function of soil microbiology and improve crop growth and development by cropping rotation or catching.

\subsection{Effect of Fire on Soil Microorganisms}

There is has a great influence on the quantity and the 
amount of soil microbial biomass by effect of fire. After the fire, the quantity and the amount of soil microbial biomass was lower than that of the non burning in the fire, the fire, the second year, microbial biomass increased gradually and exceeds the unburned site. Compared with burning field in spring, autumn burning field is more beneficial to the increase of the number of soil microorganisms [29]. Mainly reason is that after the fire, a lot of ground vegetation, animal and soil microorganisms was burned, this changes the plant community, soil physical properties, micro and large animal fauna and soil microbial populations. So that makes the surface of soil microbial quantity and biomass decrease. After a certain time to recover, because there is plenty of nutrition after burning, soil microbial biomass increased gradually with growth season.

\subsection{Effect of Closing Fencing on Soil Microorganisms}

The closing generally helps to increase soil microbial quantity and soil microbial biomass. After 4 years of degraded grassland fence, railing column microbes than grazing control area increased significantly, an increase of increased about $18 \%$ to $33 \%$. After closing fence for ten years, the total number of microorganisms than the column was increased by $40 \% \sim 88 \%$ [29]. Guo Mingying suggest that under different land using types, such as closing, grazing and cutting, closing the soil microbial biomass carbon is higher than grazing and mowing's, but microbial biomass nitrogen content and soil microbes is lower than grazing and cutting's. [36].

\subsection{Effects of Pollution on Soil Microorganism}

Oil pollution in the average color of microbial metabolic active characterization of the rate of change (AWCD), species diversity index and carbon source utilization number increase [37]. Falling oil pollution in soil, the polluted soil which the oil fell, bacterial biomass increased significantly, apparently falling oil on the growth of bacteria have certain stimulation. Because many of them has degradation and transformation of the role of oil pollutants. Among them, the secondary pollution is caused by largest microorganisms. Actinomycetes and fungi growth by oil pollution limits. In general, effects of oil pollution on soil has "characteristics of secondary pollution." The critical value of grassland soil petroleum pollution was $5 \% \sim 6 \%$ [29]. When the soil is polluted by heavy metal which has higher concentration, the soil microbial biomass will decrease significantly [38].

\subsection{Effects of Tourism Trampling on Soil Microorganism}

Serious human tourism trampling activities than that of not trample on the original reserve of soil microbial biomass carbon, nitrogen, and phosphorus were decreased by $52 \%$, $79 \%, 62 \%$ [39], therefore, tourism trampling significantly reduced soil microbial biomass.

In summary, there is a close relationship between soil microbes and the influence factors. This response interaction results may both competitive relationship and mutually beneficial relations. However, from the development of the ecological system, competition is not unfavorable factors on microorganism, but also the necessary. It is actually a kind of reciprocity that microbial fixed nitrogen behavior not only slow down the leaching loss of nitrogen, at the same time during the growing season by inorganic nitrogen uptake by plants release form [5]. Therefore, competition is the coexistence basic of foundation and development.

\section{Conclusion}

From the current progress of study on soil microbiology, although there are many reports about soil microbiology, overall it is still limited, the related research of soil microbiology may also need further exploration from the following aspects:

1) Soil Microbiology in the past mainly in agriculture, grassland, forest. The study on soil microbial secondary succession process is relatively less, especially on soil microorganism of arid secondary grassland research is not reported. But in fact, we during our work on using and rebuilding the vegetation, it is concerned about the problem of Secondary succession. Therefore, we need to research for different climate zones, different plant communities and soil type, soil microbial dynamics of secondary succession in different soil depth and adjusting mechanism.

2) Deeply research for Effect factor on the soil microbial uncertainty, such as fertilizer, temperature, closing, tillage methods, strengthen the study of carbon dioxide concentration on soil microbial biomass of other factors such as pollution. According to the research in arid area in Minqin Oasis, the research results showed that the temperature and the closing have a promoting effect on soil microorganisms, the soil microbial biomass carbon increased significantly by prolongation of closing [40]. Other uncertain factors still need further researching and discussing.

It has not only economic significance, but also ecological significance. So study needs further strengthening. Although our research group does some work about it, it is not enough [41-44].

Although the research on soil microbiology of China has made significant progress, compared with similar international research, its depth is still not enough, and most research mainly focuses on artificial management effects on soil microbiological factor and the general change. It lacks the deep research of soil ecological service function's change. In addition, there is a very large ascendant space in terms of research methods and theoretical innovation in China [45].

\section{Acknowledgements}

We gratefully acknowledge the funding received fromthe Natural Science Foundation of China (31760709) and Gansu provincial project (20JR10RA468) and Gansu provincial forestry science project $(2017 \mathrm{kj} 025)$. 


\section{References}

[1] Petersen D G, Blazewicz S J, Firestone M, Herman D J, Turetsky M, Walrop M. (2012) Abundance of microbial genes associated with nitrogen cycling as indices of biogeochemical process rates across a vegetation gradient in Alaska. Environmental Microbiology, 14: 993-1008.

[2] Pratscher J, Dumont M G, Conrad R. (2011) Ammonia oxidation coupled to $\mathrm{CO} 2$ fixation by archaea and bacteria in an agricultural soil. Proceedings of the National Academy of Sciences of the United States of America, 108: 4170-4175.

[3] Jackson L E, Bowles T M, Hodson A K, Lazcano C. (2012) Soil Microbial-root and Microbial-rhizosphere Processes to Increase Nitrogen Availability and Retention in Agroecosystems. Current Opi nion in Enviromental Sustainability, 4: 517-522.

[4] Hadar Y, Papadopoulou K K. (2012) Suppressive Composts: Microbial Ecology Links Between Abiotic Environments and Healthy Plants. The Annual Review of Phytopathology, 50: 133-153.

[5] Kuzyakov Y, Xu X. (2013) Competition Between Roots and Microorganisms for Nitrogen: Mechanisms and Ecological Relevance. New Phytologist, 198: 656-669.

[6] Xu GH, Zheng HY. (1986) Soil Microbial Analysis Handbook. Beijing: China Agriculture Press, 1986.

[7] Whitman W B, Coleman D C, Wiebe W J. Prokaryotes: The Unseen Majority (1998). Proceedings of the National Academy of Sciences of the United States of America, 95 (12): 6578-6583.

[8] Khan K S. (1998) Effects of Cadmium, Lead and Zinc Pollution on Microbial Biomass in Red Soil. Hang- zhou: Zhejiang Agricultural University, 1998.

[9] Zhang CX, Nan ZB. (2010) Research Progress of Soil Microbial Biomass. Pratacultural Science, 27 (6): 50-57.

[10] Jin ZZ, Lei JQ, Li SY, Wu XW. (2014) Characteristics of Sandy Soil Microbial Metabolisms in the Forests Drip-irrigated with Saline Water, Journal of Desert Research, 34 (2): 363-370.

[11] Smith J L, Paul E A. (1991) The significance of soil microbial biomass estimations. Bollag J M, Stotzky G Soil Biochemistry. V. 6. New York: Marcel Dekker, INC, 359-396.

[12] Tan HW, Yang SD, Wu Jun, Liu YX, Xiong LM, Zhou LQ, Xie RL, Huang GQ, Zhao QG. (2014) Comparison of Eucalyptus plantation with and other forests in soil microbial activity and bacterial diversity in red soil region, China. Acta Pedologica Sinica, 51 (3): 575-584.

[13] Liu Li, Xu MK, Wang SL, Zhang QR, Wang Nan, Pan HQ, $\mathrm{Hu}$ JC. (2013) Effect of different Cunninghamia lanceolata plantation soil qualities on soil microbial community structure. Acta Ecologica Sinica, 33 (15): 4692-4706.

[14] Guo JH, Liu ZJ, Zhang Y, et al. (2010) Significant acidification in major Chinese croplands. Science, 2010, 32 7: 1008-1010.

[15] Rousk J, Bååth E, Brookes P C, et al. (2010) Soil bacterial and fungal communities across a $\mathrm{pH}$ gradient in an arable soil. The ISME Journal, 4: 1340-1351.
[16] Wendu Rile, Li Gang, Zhang JN, Lai Xin, Yi Jin, Fan GY, Yang DL. (2010) The study of soil microbial biomass and soil enzyme avtivity on different grassland in Hulunbeier, Inner Mongolia. Acta prataculturae Sinica, 19 (5): 94-102.

[17] Gao L H, Qu M, Ren H Z, et al. (2010) Structure, function, application, and ecological benefit of a singleslope, energy-efficient solar greenhouse in China. Hort Technology, 20: 626-631.

[18] Jenkinson D S. Determination of microbial biomass carbon and nitrogen in soil. (1988) Wlson J R. Advances in Nitrogen Cycing in Agricuitural Ecosystems. Walltingford, England: CAB International, 368-386.

[19] Li CH, Zhang CX, Tang LS, Xiong ZQ, Wang BZ, Jia ZJ, Li Yan. (2014) Effect of long-term fertilizing regime on soil microbial diversity and soil property. Acta Microbiologica Sinica, 54 (3): 319-329.

[20] Wei Wei, Xu YL, Zhu Lin, Han XZ, Li S. (2013) Effect of long-term fertilization on soil microbial communities in farmland of black soil. Acta Pedologica Sinica, 50 (2): 372-380.

[21] Chen LM, Lu JL, Gui LG, Wang SR, Liu NN. (2006) Studies on soil microbial biomass carbon, nitrogen, phosphorus and maize yield in newly cultivated light sierozem. Agricultural Research in the Arid Areas, 24 (20): 48-51.

[22] Lu Lei, Li ZP, Che YP. (2006) Effects of different fertilization treatments on soil microbial biomass and enzyme activities in Hapli-Stagnic anthrosols. Soil, 38 (3): 309-314.

[23] Li Zheng, Liu GS, Jing HX, Ye XF, Xie CS, Xiang YG, Zhang WP, Yang Chao, Wang Yong, Xi XY. (2011) Effects of Green Manure Application Combined with Chemical Fertilizers on Microbial Biomass $\mathrm{C}, \mathrm{N}$ and Nitrogen Supplying Characteristics of Tobacco-Planting Soils. Acta prataculturae Sinica, 20 (6): 126-134.

[24] Zhang CG, Wang SQ. (2000) Study on Soil Microbial Biomass during Decomposition of Crop Straws. Journal of Soil and Water Conservation, 14 (3): 96-99.

[25] Li CH, Jia ZJ, Tang LS, Wu YC, Li Yan. (2012) Effect of model of fertilization on microbial abundance and enzyme activity in oasis farmland soil. Acta Pedologica Sinica, 49 (3): 567-574.

[26] Zhang H, Lu JL, Cao YF, et al. (2014) Decomposition characteristics of different plant straws and soil microbial functional diversity. Acta Pedologica Sinica, 51 (4): 743-752.

[27] Tian YQ, Gao LH. (2012) Research progress on catch crop planting for reducing soil function degradation in greenhouse vegetable field. China vegetables, 32 (18): 26-35.

[28] Zhou DB, Jin Tao, Tan Xin, et al. (2013) Effect of antagonistic bacteria and soil disinfectant on soil bacterium community in banana fusarium wilt disease area. Acta Microbiologica Sinica 53 (8): 842-851.

[29] Zhao Ji, Liao YN, Zhang GZ, Shao YQ. (1999) Soil Microbial Ecology on the Grassland Ecosystem. Grassland of China, (3): 57-67.

[30] Bardgett R D, Leemans D K, Cook R, et al. (1997) Seasonality in the soil biota of grazed and ungrazed hill grasslands. Soil Biology \& Biochemistry, 29: 1285-1294. 
[31] Holt J A. (1997) Grazing pressure and soil carbon, microbial biomass and enzyme activities in semi-arid northeastern Australia. Applied Soil Ecology, (5): 143-149.

[32] Cao SB, Liu QW, Wang LQ, et al. (2012) Effect of short-term grazing on soil microorganisms and soil enzyme activities in Meadow Steppe. Microbiology China, 39 (6): 0741 0748.

[33] Mawdsley J L, Bardgett R D. (1997) Continuous defoliation of perennial ryegrass (Lolium perenne) and white clover (Trifolium repens) and associated changes in the microbial population of an upland grassland soil. Biology and Fertility of Soils, 24: 52-58.

[34] Xu YC, Shen QR, Ran W. (2002) Effects of long-term no-tillage and organic fertilizer application on soil microbial biomass carbon, nitrogen and phosphorus. Acta Pedologica Sinica, 2002, 39 (1): 89-96.

[35] Zhang LH, Huang GB, Zhang RZ. (2006) Effect of no-tillage on soil microbial biomass carbon, Nitrogen and phosphorus under dry farming [J]. Gansu Agricultural Science and Technology, (12): 3-6.

[36] Guo MY, Zhao KT, You JC, Xu LJ, Wang LJ, Ja SJ, Xin XP. (2012) Soil Microbial Characteristic and Soil Respiration in Grassland under Different Use Patterns. Acta Agrectir Sinica, 20 (1): $42-48$.

[37] Li Xin, Zhang HH, Yue BB, et al. (2012) Effects of Festuca arundinacea on the microbial community in crude oil-contaminated saline-alkaline soil. Chinese Journal of Applied Ecology, 23 (12): 3414-3420.

[38] Yang QH, Liu HN, Li QH. (2012) Study on the Microbial Activity of Rhizosphere Soil for Three Dominant Plant in $\mathrm{Pb}-\mathrm{Zn}$ Wastelandin Eastern Guangdong Province. Chinese Agricultural Science Bulletin, 28 (30): 56-64.
[39] Tan ZJ, Dai SM, Xie GX, et al. (2006) Studies on the effect of recreation activities on soil microbial biomass carbon, soil microbial biomass nitrogen and soil microbial biomass phosphorus in Zhangjiajie National Forest Park. Acta Scientiae Circumstantiae, 26 (11): 1921-1926.

[40] Tian Qing, Wang JB, Zhang DG, Wang LD. (2013) Change of Soil Properties with the Restoration of Vegetation in the South Fringe of the Tengger Desert, Journal of Desert Research, V33 (3): $772-776$.

[41] Zhang Y, Zhu Y, Yao T, Qi J, Rong LY. (2013) Interactions of Four PGPRs Isolated From Pasture Rhizosphere. Acta prataculturae Sinica, 22 (1): 29-37.

[42] Han HW, Sun LN, Yao Tuo, Zhang Ying, Wang GJ. (2013) Effects of Effective Microbial Inoculants on Alfalfa Growth Character. Acta Agrestia Sinica, 21 (2): 353-359.

[43] Rong LY, Yao Tuo, Huang GB, Chai Qiang, Liu QH, Han HW, $\mathrm{Lu}$ Hu. (2013) Screening of plant growth promoting rhizobacteria strains and effects of inoculant on growth of maize by replacing part of chemical fertilizers. Agricultural Research in the Arid Areas, 31 (2): 59-65.

[44] Sun GZ, Yao Tuo, Liu Ting, Lu Hu. (2014) Antagonism of plant growth promoting rhizobacteria on three soil-borne fungous pathogen. Microbiology China, 41 (11): 2293 2300.

[45] Berendsen R L, Pieterse C M J, Bakker P A H M. (2012) The rhizosphere microbiome and plant health. Trends in Plant Science, 17: 478-486. 